\title{
Functional connectivity of brain network during character imagery Qingbao $\mathrm{Yu}^{1}$ and Yi-Yuan Tang*1,2
}

\author{
Address: ${ }^{1}$ Institute of Neuroinformatics and Laboratory for Brain and Mind, Dalian University of Technology, Dalian 116024, China and \\ ${ }^{2}$ Department of Psychology, University of Oregon, Eugene, OR 97403, USA \\ Email: Yi-Yuan Tang* - yiyuan@uoregon.edu \\ * Corresponding author
}

from Seventeenth Annual Computational Neuroscience Meeting: CNS*2008 Portland, OR, USA. 19-24 July 2008

Published: II July 2008

BMC Neuroscience 2008, 9(SuppI I):PI57 doi:I0.I I86/I47I-2202-9-SI-PI57

This abstract is available from: http://www.biomedcentral.com/I47I-2202/9/SI/PI57

(c) 2008 Yu and Tang; licensee BioMed Central Ltd.

\section{Background}

Previous results indicate cognitive processes of brain areas usually activate during visual mental imagery [1], however, few studies address the functional connectivity between these active regions. In the present study, a lowfrequency $(0-0.15 \mathrm{~Hz})$ coherence method was used to analyze the event-related fMRI data from a task in which participants visualized digits and letters (termed as character imagery). The coherence method was discussed in detail in Sun et al [2]. A band-averaged coherence of 1 would indicate strong functional interaction between areas, and a coherence of 0 would indicate the total absence of such a relationship [2]. The brain networks include left IFG (inferior frontal gyrus), left FUS (fusiform gyrus), left CUN (cuneus) and left SPL (superior parietal lobule). All of the four ROIs (Regions of Interest) were selected based on previous studies [1,3]. Nine righthanded subjects participated in this study. The materials of the character imagery task were based on a subset of those used by Kosslyn et al [4]. Statistical parametric mapping analysis was performed using SPM2 running under Matlab 6.5.
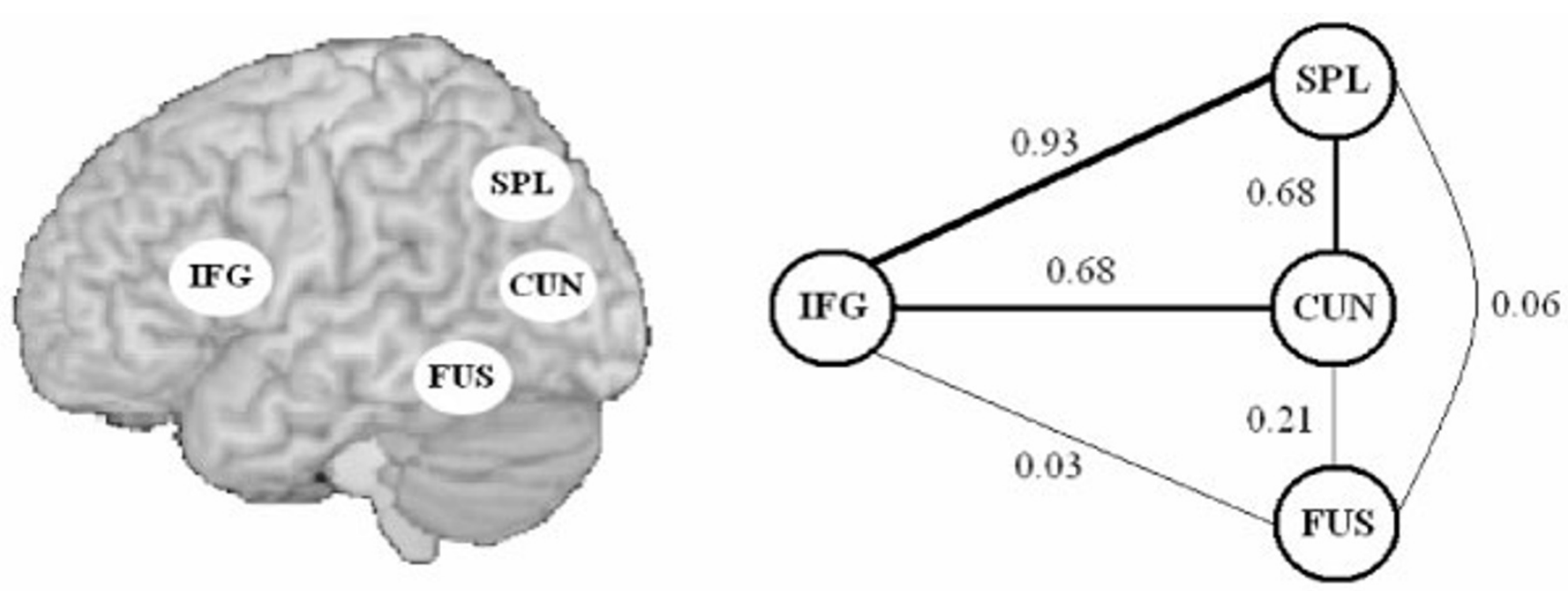

Figure I

Schematic locations of the four ROls (left) and the results of low-frequency $(0-0.15 \mathrm{~Hz})$ coherence analysis (right). The thick black lines indicate strong coherence between the two areas; the thin lines indicate weak coherence. 


\section{Results and conclusion}

All of the four ROIs were activated during character imagery in the present study as anticipated. The schematic locations of the four ROIs and the results of low-frequency $(0-0.15 \mathrm{~Hz})$ coherence analysis are shown in Figure 1. Our results indicated that the left IFG, the left SPL and the left CUN had strong functional connectivity, whereas the functional connectivity between the left FUS and any one of the other three ROIs was weak. These results suggested that the four ROIs were not equally associated during character imagery.

\section{Acknowledgements}

We thank Drs. Stephen M Kosslyn, William L Thompson, Giorgio Ganis at Harvard University for generously providing imaging data and insightful comments. We thank Dr. Lee M. Miller for helpful suggestions about the low-frequency coherence analysis method. This work was supported in part by National Natural Science Foundation of China Grant 30670699, Ministry of Education Grant NCET-06-0277 and 021010.

\section{References}

I. Thompson WL, Kosslyn SM: Neural systems activated during visual mental imagery: A review and meta-analyses. In Brain mapping II: The systems Edited by: Mazziotta J, Toga A. New York: Academic Press; 2000:535-560.

2. Sun FT, Miller LM, D'Esposito M: Measuring interregional functional connectivity using coherence and partial coherence analyses of fMRI data. Neuroimage 2004, 2 I:647-658.

3. James $\mathrm{KH}$, Gauthier I: Letter processing automatically recruits a sensory-motor brain network. Neuropsychologia 2006, 44(I 4):2937-2949.

4. Kosslyn SM, Thompson WL, Shephard JM, Ganis G, Bell D, Danovitch J, Wittenberg LA, Alpert NM: Brain rCBF and performance in visual imagery tasks: Common and distinct processes. The European Journal of Cognitive Psychology 2004, 16(5696-716 [http:// dx.doi.org// $0.1080 / 0954 \mid 440340000475]$.
Publish with Biomed Central and every scientist can read your work free of charge

"BioMed Central will be the most significant development for disseminating the results of biomedical research in our lifetime."

Sir Paul Nurse, Cancer Research UK

Your research papers will be:

- available free of charge to the entire biomedical community

- peer reviewed and published immediately upon acceptance

- cited in PubMed and archived on PubMed Central

- yours - you keep the copyright

Submit your manuscript here:

http://www.biomedcentral.com/info/publishing_adv.asp
BioMedcentral 